\title{
Investigations of surface morphology and chemical composition of Ag/ZnS/glassceramic thin-film structure
}

\author{
D. Kurbatov ${ }^{1}$, A. Opanasyuk ${ }^{1}$, V. Denisenko ${ }^{2}$, A. Kramchenkov ${ }^{2}$, M. Zaharets ${ }^{2}$ \\ ${ }^{1}$ Sumy State University, Department of General and Experimental Physics, \\ 2, Rimsky-Korsakov str., 40007 Sumy, Ukraine, e-mail: kurd@ukr.net \\ ${ }^{2}$ Applied Physics Instiute, 58, Petropavlovskaya str., 40030 Sumy, Ukraine
}

\begin{abstract}
The surface morphology and chemical composition of $\mathrm{Ag} / \mathrm{ZnS} /$ glassceramic thin-film system obtained by close-spaced vacuum sublimation technique under different grow conditions were investigated. Examination of surface profile and morphology was performed by scanning electron and optical microscopy. Chemical composition was studied by Rutherford back scattering method. Results of morphology studies enabled to determine dependence of the growth mechanism, roughness $R_{a}$, grain size $D$ of $\mathrm{ZnS}$ layers on the growth conditions. The researches of chemical composition allowed to determine the concentration of compound elements and impurities, deviation from stoichiometry and thickness distribution of chemical elements.
\end{abstract}

Keywords: zinc sulfide, thin films, surface morphology, roughness, Rutherford backscattering spectroscopy, chemical composition, thickness distribution.

Manuscript received 03.06.08; accepted for publication 20.06.08; published online 15.09.08.

\section{Introduction}

Thin-film solar cells with $\mathrm{Cu}\left(\operatorname{In}_{1-\mathrm{x}} \mathrm{Ga}_{\mathrm{x}}\right) \mathrm{Se}_{2}$ (CIGS) and $\mathrm{CuInS}_{2}$ (CIS) absorbers have achieved high efficiencies in recent years. Cadmium sulfide $(\mathrm{CdS})$ buffer layers prepared by chemical bath deposition (CBD) are commonly used in CIGS or CIS-based cells. Even though cells with the $\mathrm{ZnO} / \mathrm{CBD}-\mathrm{CdS} / \mathrm{CIGS}$ structure have high efficiencies $(\eta=19.6 \%)$, manufacturing companies have sought alternatives to the CBD-CdS buffer layer, which could eliminate the use of $\mathrm{Cd}$ ("Cd-free") and improve the collection of carriers generated by shortwave light [1]. One promising alternative material is $\mathrm{ZnS}$. Its bandgap energy $\left(E_{g}\right)$ of $3.68 \mathrm{eV}$ makes it transparent to practically all wavelengths of the solar spectrum. In contrast, $\mathrm{CdS}$ with its bandgap of $2.4 \mathrm{eV}$ is highly absorbing for wavelengths below $520 \mathrm{~nm}$.

There has been a considerable progress in using CBD-ZnS in CIGS-based thin-film solar cells. The best efficiency of $\mathrm{ZnO} / \mathrm{CBD}-\mathrm{ZnS} / \mathrm{CIGS}$ solar cells increased to $18.6 \%$ [2] in recent years. As one of the possibilities of efficiency improving, there is chemically pure growth of $\mathrm{ZnS}$ buffer layer with a high coefficient of optical transmission. But it is possible only by replacing the deposition method to receive condensates, since according the literature $\mathrm{CBD}-\mathrm{ZnS}$ contains significant amounts of oxygen in the form of $\mathrm{ZnO}$ and/or $\mathrm{Zn}(\mathrm{OH})_{2}$ in its composition.
This work is devoted to chemical composition and morphology studies of $\mathrm{ZnS}$ thin films obtained by closespaced vacuum sublimation technique (CSVS) under different grow conditions. It is considered that the closespaced vacuum evaporation method (CSVE) may become successful alternative to $\mathrm{CBD}$ method for producing the ZnS-based window layer of solar cells with improved characteristics [3].

Under the deposition of $\mathrm{ZnS}$ films exercisable as basic layers of solar cells, the optimization of film characteristics is very important. These condensates on cheap glass substrates must have monophase columned structure with low level of non-controlled impurities and composition close to stoichiometric. It stipulated the aim of this paper.

\section{Experimental details}

Thin ZnS films were obtained by CSVE method [4]. The refined glassceramic plates were used as substrates. The evaporation of two-phase stoichiometric $\mathrm{ZnS}$ powder was carried out. The temperature $T_{e}$ of the evaporator was $1373 \mathrm{~K}$. The temperature $T_{s}$ of substrate was varied within the range 373 to $973 \mathrm{~K}$. The time $t$ of layer condensation was $300 \mathrm{~s}$. The thickness of films $L$ was varied within the range 0.2 to $7 \mu \mathrm{m}$. Geometry of our samples was determined by the mask in-use. Usually they had a shape of a circle with a diameter $10 \mathrm{~mm}$. The 
thin $\mathrm{Ag}$ layer was applied on the $\mathrm{ZnS}$ film to support gathering the charge from the film surface during measurements using charge particles. Under these conditions, the temperature of the $\mathrm{ZnS}$ surface was $373 \mathrm{~K}$.

The morphology of $\mathrm{ZnS}$ films surface was investigated by scanning electron (SEM 103-01) and optical microscopy. The average grain size $D$ inside the layers was determined by the Jeffries method by using the formula $D=k \sqrt{S / M^{-2} n}$, where $k$ is the coefficient of grain shape, $S$ - the area of the section in a micrograph; $M$ - magnification; $n$ - the number of grains in a chosen plot. The calculation of surface roughness was performed according to the standard ISO/R 468 [5], while the average arithmetic deviation $R_{a}$ of profile was defined by formula $R_{a}=\frac{1}{n} \sum_{i=1}^{n} y_{i}$, where $y_{i}$ - profile deviation of film surface from the mean line, $n-$ the number of profile peaks.

To determine elemental composition of $\mathrm{Ag} / \mathrm{ZnS} /$ glassceramic, the Rutherford backscattering method (RBS) of protons was used [6]. As the source of charged particles, the electrostatic accelerator on $1 \mathrm{MeV}$ (Institute of Applied Physics, NAS of Ukraine) was utilized. The primary beam of protons bombarded the target normally, scattering angle was $135^{\circ}$. As the detecting system, the magnetic spectrometer and $\mathrm{Si}$ detector of charged particles were used. This magnetic spectrometer allowed to enhance the energy resolution to $3.2 \mathrm{keV}$.

The RBS spectra processing was performed by the SIMNRA program. Determination of the impurity concentration and component depth profiles for this compound was fulfilled by means of standard technique [7].

\section{Results and discussion}

As a result of pursued researches of $\mathrm{ZnS}$ films in $\mathrm{Ag} / \mathrm{ZnS} /$ glassceramic structure surface morphology, it was determined that these films are polycrystalline, homogeneous along the samples area and they have good adhesion to substrate for deposition temperatures $T_{s}>300 \mathrm{~K}$ (Fig. 1). At low temperatures the film substrates were fine-crystalline $(D<0.1 \mu \mathrm{m})$. Through intensive secondary nucleation, at the same time growth of crystallite dimensions with increasing of film thicknesses almost didn't take place.

With increasing $T_{s}$, the growth mechanism varied, and the films began to grow according to the columnlike mechanism. While increasing $T_{s}$ from 323 to $993 \mathrm{~K}$, the average size $D$ of crystallite in the film plane grew from $0.1 \mu \mathrm{m}$ to $1-2 \mu \mathrm{m}$ at $L \sim 3 \mu \mathrm{m}$. $D$ increase occurred also while $L$ increasing. Under conditions close to thermodynamic equilibrium, the films were practically monoblock along the layer thickness.

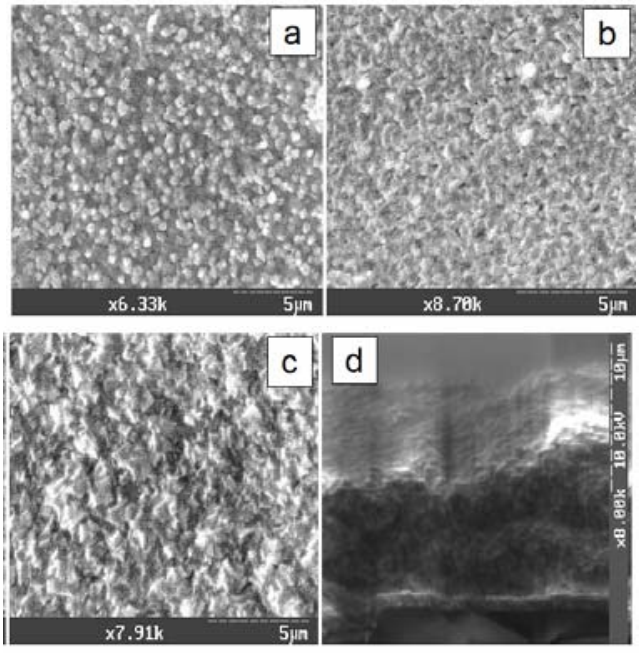

Fig. 1. Microstructure of $\mathrm{ZnS}$ films: surface morphology of the films grown under various substrate temperatures: $T_{s}=$ 393 K (a); 573 (b); 993 (c); and their cross-section (d).

The investigation of optical characteristics of condensates [8] demonstrated that for the wavelength $\lambda$ greater than 350-360 nm the significant enhancement of the transmission coefficient occurred and for $\lambda$ greater than $450-500 \mathrm{~nm}$ all the films had a very high transmission coefficient that ran up to $85-95 \%$. This argues about availability to use vacuum $\mathrm{ZnS}$ condensates as a high-energy gap window of thin-film solar cells.
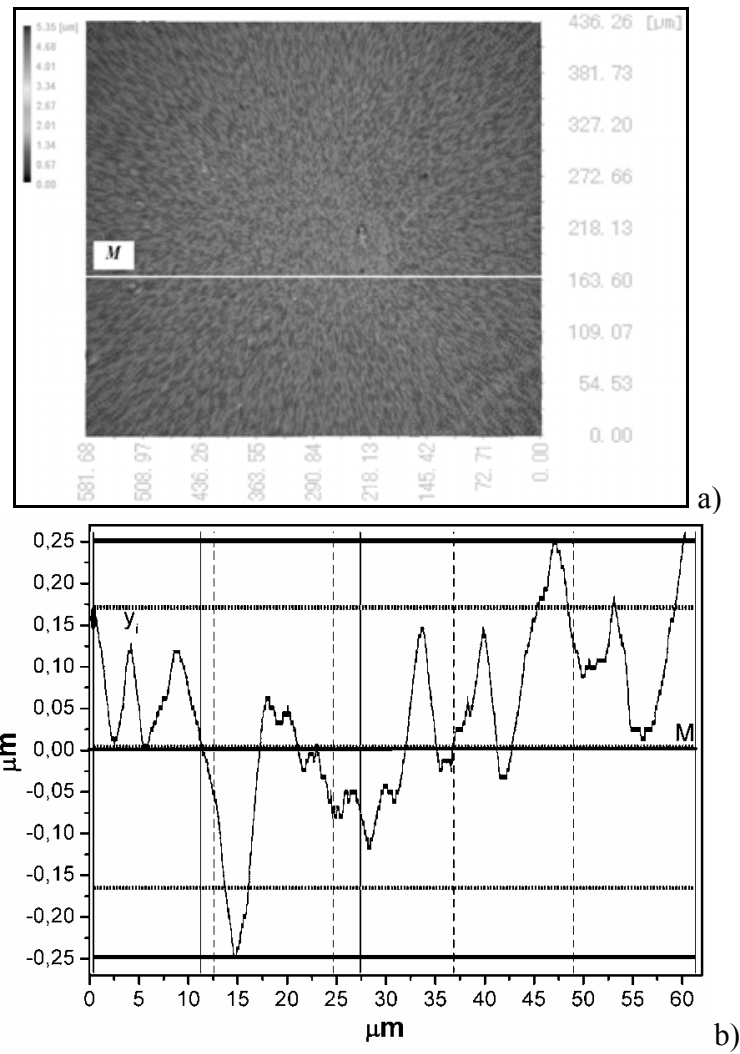

Fig. 2. Typical optical migrograph of the $\mathrm{ZnS}$ film (a) grown under $T_{s}=863 \mathrm{~K}$ and profile of the surface part (b). 
The surface morphology investigation of $\mathrm{ZnS}$ films, fulfilled in this work, revealed that the rise of the condensation temperature is going with increase in height of layers relief and therefore its surface roughness. The typical micrographs of condensate surfaces and surface profilograms are presented in Fig. 2. For quantitative estimation of films roughness by using the profilograms, the calculation of average arithmetic deviations of profiles $R_{a}$ from the average line was performed.

Determination of the parameter $R_{a}$ shows that under rising temperature from $T_{s}=423 \mathrm{~K}$ to $863 \mathrm{~K}$ the surface roughness is increased from $R_{a} \approx 0.062 \mu \mathrm{m}$ to $0.147 \mu \mathrm{m}$ at $L \sim 3 \mu \mathrm{m}$. The dependence of the profile average arithmetic deviation for $\mathrm{ZnS}$ films versus $T_{S}$ is shown in Fig. 3.

In Fig. 3, two regions of temperature with different $R_{a}$ - dependences on the temperature $T_{s}$ might be indicated. Their presence may be explained by changing the mechanism of $\mathrm{ZnS}$ films growth under $T_{s}>650$ $700 \mathrm{~K}$. The sharper arising of average arithmetic deviation $R_{a}$ of films surface profile occurs in the range of deposition temperature, where the column mechanism of film growth is realized.

It is known that solar cells with heterojunctions are fabricated in two configurations: back- and frontalbarriered. The maximal efficiency is inherent to backbarriered structures, where the electrically conductive transparent layer of $\mathrm{ZnO}\left(\mathrm{SnO}_{2}\right)$ or its analogue is initially deposited on the glass substrates, then $\mathrm{ZnS}$ buffer layer follows and finally the basic light-absorbing layer (CIGS or CdTe) with current-collecting contact completes the block. Using $\mathrm{ZnS}$ films with the columned structure and comprehensive surface relief must promote improving the efficiency of corresponding solar cells through reduction of reflectivity factor from basic layer surface and series connected resistance relating to presence of grain boundary.

The typical proton-scattering spectra obtained from films deposited under various physical and technological conditions are represented in Fig. 4a. In Fig. 4b, the simulated with program package SIMNRA [9] RBS spectra accompanied with the measured ones are represented. The reconstruction degree of experimental spectra is very high. As shown in Fig. 4, the elements that belong to substrate and current-collecting contact contribute to RBS spectra besides $\mathrm{ZnS}$ compound.

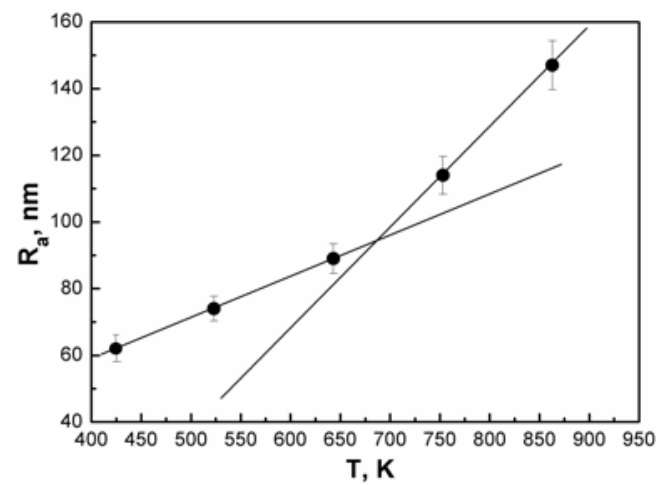

Fig. 3. The average arithmetic film profile deviation $R_{a}$ vs $T_{s}$.
After processing RBS spectra of $\mathrm{ZnS}$, silicon was found near the substrate (we assume that $\mathrm{Si}$ atoms diffused from glassceramic to halcogenide under high temperatures of condensation). The small amount of $\mathrm{W}$ $(\sim 1-2 \%)$ is also on film surface, and it is obviously caused by tungsten evaporator. It is known that the RBS method has a high sensitivity to elements with large atomic number, therefore $\mathrm{W}$ is registered despite very small concentration. The oxygen is found only close to the substrate and in the near-surface film layer where oxide phases ( $\mathrm{ZnO}$ for example) may be formed in the air. It is necessary to mark that in $\mathrm{ZnS}$ films obtained by the pyrolitic method and from chemical solutions the oxygen amount dissolved in halcogenide may run up to 3-8 \% and such films can be rather considered to be a solid solution $\mathrm{ZnS}_{\mathrm{x}} \mathrm{O}_{1-\mathrm{x}}$ or mixture $\mathrm{ZnS}, \mathrm{Zn}(\mathrm{OH})_{2}$ and $\mathrm{ZnO}$ [10]. In vacuum condensates, the oxygen amount don't exceed 1-2\% (usually). That is registered experimentally. Although the carbon trace $(<1 \%)$ is detected on examined films surface but, as the additional investigation argues, this element penetrates into the sample from vacuum oil.
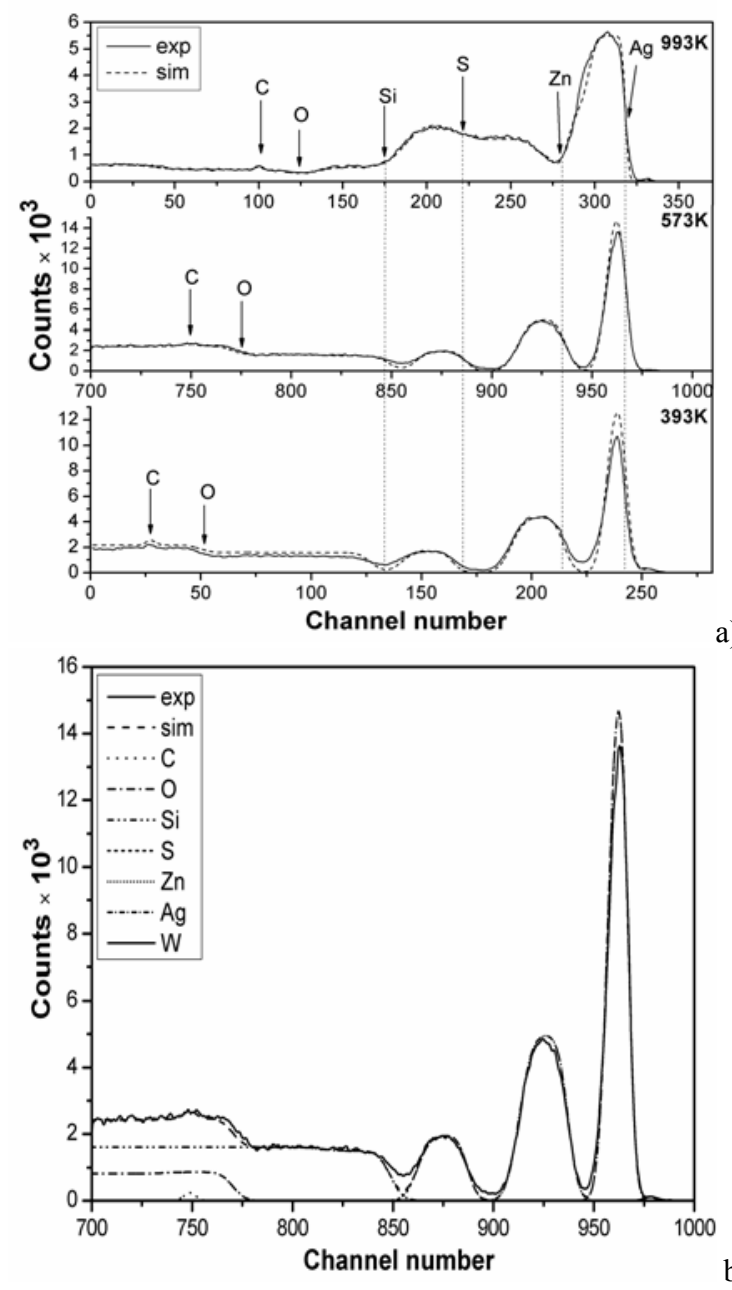

Fig. 4. RBS spectra of $1 \mathrm{MeV}$ protons, scattered from $\mathrm{Ag} / \mathrm{ZnS} /$ glassceramic (a) and example of simulation pattern at $T_{s}=573 \mathrm{~K}(\mathrm{~b})$.

(C) 2008, V. Lashkaryov Institute of Semiconductor Physics, National Academy of Sciences of Ukraine 
RBS spectra analysis enabled to calculate the layer thickness and component concentrations of compound. The $\mathrm{ZnS}$ film thickness is determined from the relationship:

$$
L=\frac{\Delta E}{[\bar{\varepsilon}]_{\mathrm{ZnS}} \cdot n_{\mathrm{ZnS}}},
$$

were $\Delta E$ is the energy width of a peak; $n_{\mathrm{ZnS}}$ concentration of $\mathrm{ZnS}$ compound; $[\bar{\varepsilon}]_{\mathrm{ZnS}}$ - "stopping" cross-section of $\mathrm{ZnS}$ calculated from Bragg's rule through "stopping" cross-sections of the different compound elements:

$$
\begin{gathered}
{[\bar{\varepsilon}]_{\mathrm{ZnS}}=[\bar{\varepsilon}]_{\mathrm{Zn}} c_{1}+[\bar{\varepsilon}]_{\mathrm{S}} c_{2},} \\
n_{\mathrm{ZnS}}=\frac{\rho_{\mathrm{Zn}} c_{1}+\rho_{\mathrm{S}} c_{2}}{A_{\mathrm{Zn}} c_{1}+A_{\mathrm{S}} s_{2}} N_{A},
\end{gathered}
$$

here $\rho_{Z n}, \rho_{S}$ are the densities of individual elements, respectively; $A_{\mathrm{Zn}}, A_{\mathrm{S}}$ are their atomic masses; $c_{1}$ and $c_{2}-$ weighting factors.

The film thicknesses average ratio of atomic concentrations of compound components was determined using the formulae

$$
\gamma=\frac{C_{\mathrm{Zn}}}{C_{\mathrm{S}}}=\frac{\sigma_{\mathrm{S}} H_{\mathrm{Zn}} \Delta E_{\mathrm{Zn}}}{\sigma_{\mathrm{Zn}} H_{\mathrm{S}} \Delta E_{\mathrm{S}}}, c_{1}=\frac{\gamma}{1+\gamma}, c_{2}=\frac{\gamma}{1+\gamma},
$$

where $C_{\mathrm{Zn}}, C_{\mathrm{S}}$ are atomic percentage of $\mathrm{Zn}$ and $\mathrm{S}$, respectively; $\sigma_{\mathrm{Zn}}, \sigma_{\mathrm{S}}-$ cross-sections of protons scattered by $\mathrm{Zn}$ and $\mathrm{S} ; \Delta E_{\mathrm{Zn}}, \Delta E_{\mathrm{S}}$ - energetic width (FWHM) of a peak for $\mathrm{Zn}$ and $\mathrm{S}$, respectively; $H_{\mathrm{Zn}}$, $H_{\mathrm{S}}$ - the magnitudes of a signal for $\mathrm{Zn}$ and $\mathrm{S}$, respectively.

For the RBS data, the thicknesses of $\mathrm{ZnS}$ films were determined. The spectra of these films are shown in Fig. 4. The thicknesses L are $194 \pm 5,178 \pm 5$, and $450 \pm 5 \mathrm{~nm}$ for the samples deposited under temperatures $\mathrm{T}_{\mathrm{s}}$ equal to 393,573 , and $993 \mathrm{~K}$, respectively.

The investigations show that for $\mathrm{L}>300 \mathrm{~nm}$ and proton energies $E_{0}=1 \mathrm{MeV}$ overlapping of partial peaks takes place that complicates the data processing. In fact, Fig. 4a shows that peaks are separated for $\mathrm{L}=178 \mathrm{~nm}$ and $194 \mathrm{~nm}$, but for $\mathrm{L}=450 \mathrm{~nm}$ peaks are overlapped.

RBS method also allows determining the depth profile of layer components. For the case when partial peaks are separated on RBS spectra, the component concentrations of compound, ratio $\gamma$ and stoichiometry changes with the layer thickness were calculated. With this, it was considered that the condensates are area homogeneous.

In Fig. 5, the $\mathrm{Zn}$-to-S ratios of $\mathrm{ZnS}$ compound as a function of depth for temperatures $T_{s}=393 \mathrm{~K}$ and $573 \mathrm{~K}$ are represented.

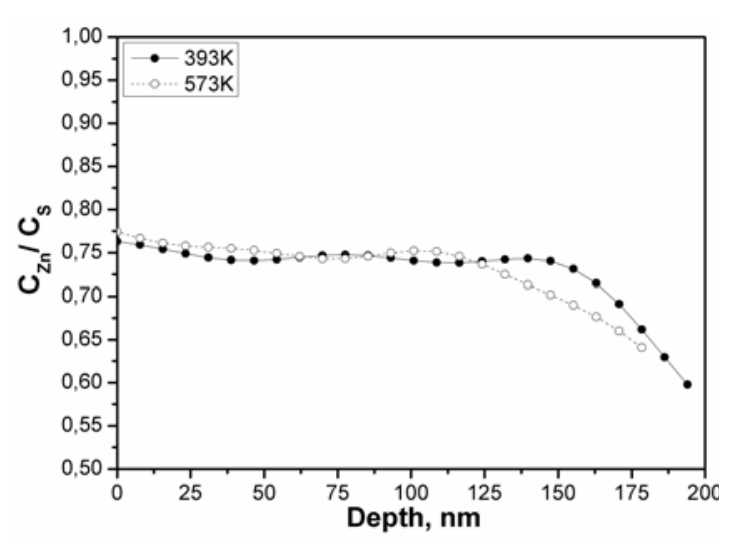

Fig. 5. Dependence of $\mathrm{ZnS}$ films stoichiometry on depth for $\mathrm{Ag} / \mathrm{ZnS} /$ glassceramic structure.

As seen from Fig. 5, layer stoichiometry is lightly varying with depth, and the $\mathrm{S}$ concentration is increased in the interlayer that adjoins the substrate. It is the evidence of evaporation incongruence of $\mathrm{ZnS}$ compound under deposition process. It appears also that condensate stoichiometry is determined by the substrate temperature $T_{s}$ and depends on the film thickness. The stoichiometry depending on these parameters was varying from 0.72 to 1.07. The obtained ratios of the component concentrations for $\mathrm{ZnS}$ films $(\gamma \sim 0.72)$ are somewhat unexpected and require refinement using other methods. The analogous data are published only in the paper [11]. It will be possible in the case of RBS data that $\mathrm{ZnS}$ films must be two-phase and contain inclusions of S. But this contradicts results of X-ray diffraction study and scanning electron and optical microscopy. By means of these methods the $\mathrm{S}$ precipitates are not detected in films. But it is necessary to point out that our X-ray diffraction and electron microscopy investigations were fulfilled using more thick films $(L \sim 3-5 \mu \mathrm{m})$. The concentration ratios $\gamma=1.07$ found for these films $(L=450 \mathrm{~nm})$ correspond to published data. As a rule, $\mathrm{ZnS}$ films obtained by various methods reveal the $\mathrm{Zn}$ excess [12-14].

The interdiffusion of elements was observed in the interface between $\mathrm{Ag}$ and $\mathrm{ZnS}$ that is related with applying the metal contact over heated substrate. While the calculation results of "spreading" magnitudes of $\mathrm{Zn}$ and $\mathrm{S}$ distribution profiles in this transition layer are quantitatively and qualitatively harmonized with the data of film surface roughness measurements.

\section{Conclusions}

The surface morphology investigation and nondestructive elemental analysis of many-layer $\mathrm{Ag} / \mathrm{ZnS} /$ glassceramic structure obtained by close-spaced vacuum sublimation technique under different grow temperatures were carried out. Two temperature ranges where the film growth is realized by different mechanisms were determined. It was established that the layer surface roughness was significantly increased in the region of columned growth. 
By means of the RBS method, the elemental composition of condensates was determined, and component distribution of compound as a function of many-layer system depth was obtained. The impurities including oxygen are revealed only near the film surface and in layer contacting with substrate. It was shown that thickness averaged stoichiometry of $\mathrm{ZnS}$ films were determined by deposition regimes and were varying in Zn-to-S ratio range 0.72-1.07.

The fulfilled studies indicate the CSVS method availability of deposition of $\mathrm{ZnS}$ films, suitable for using as high-bandgap window of solar cells.

\section{Acknowledgement}

The authors would like to thank Ph.D. V. Laptev from Institute of Physical Electronics (University of Stuttgart) for optical investigations of film surfaces.

\section{References}

1. K. Ramanathan, M.A. Contreras, C.L. Perkins et al., Properties of $19.2 \%$ efficiency $\mathrm{ZnO} / \mathrm{CdS} / \mathrm{CuInGaSe}$ thin-film solar cell // Progr. Photovolt.: Res. Appl. 11, p. 225 (2003).

2. M.A. Contreras, T. Nakada, M. Hongo et al. // Proc. $3^{\text {rd }}$ World Conference of Photovoltaic Energy Conversion, Osaka, Japan, p. 570 (2003).

3. D. Hariskos, S. Spiering, M. Powalla, Buffer layers in $\mathrm{Cu}(\mathrm{In}, \mathrm{Ga}) \mathrm{Se}_{2}$ solar cells and modules // Thin Solid Films 480-481, p. 99-109 (2005).

4. Y.P.V. Subbaiah, P. Prathap, M. Devika, K.T.R. Reddy, Close-spaced evaporated ZnSe films: preparation and characterization // Physica B 365, p. $240(2005)$.
5. ISO Recommendations on Roughness Measurements. ISO/R 468, 1878, 1880, TC 57.

6. J.R. Tesma, M. Nastasi, J.C. Barbow et al., Handbook of Modern Ion Beam Materials Analysis. Materials Research Society, Pittsburgh, 1995.

7. L.C. Feldman, J.W. Mayer, Fundamentals of Surface and Thin Film Analysis. North HollandElsevier, New York, 1986.

8. D.I. Kurbatov, A.S. Opanasyuk, Optical properties $\mathrm{ZnS}$ thin films for the antireflection coating of solar cells // Visnyk Sumskogo Derzhav. Universitetu 2, p. 60-66 (2008) (in Ukrainian).

9. H.H. Andersen, J.F. Ziegler, Hydrogen Stopping Powers and Ranges in All Elements. Pergamon Press, New York, 1977.

10. A.O. Pudov, J.R. Sites, T. Nakada, Performance and loss analyses of high-efficiency chemical bath deposition (CBD)-ZnS/Cu( $\left.\operatorname{In}_{1-\mathrm{x}} \mathrm{Ga}_{\mathrm{x}}\right) \mathrm{Se}_{2}$ thin-film solar cells // Jpn J. Appl. Phys. 41(Part 2), p. 672674 (2002).

11. R. Kobayashi, N. Sato, M. Ichimura, E. Arai, Photochemical deposition of $\mathrm{ZnS}$ thin films from $\mathrm{C}_{4} \mathrm{H}_{4} \mathrm{KNaO}_{6}$-added solutions // J. Opt. and Adv. Mat. 5(4), p. 893-898 (2003).

12. H. Kashani, Production and evaluation of $\mathrm{ZnS}$ thin films by the MOCVD technique as alpha-particle detectors // Thin Solid Films 288, p. 50-56 (1996).

13. I.O. Oladeji, L. Chow, Synthesis and processing of $\mathrm{CdS} / \mathrm{ZnS}$ multilayer films for solar cell application // Thin Solid Films 474, p. 77-83 (2005).

14. S.J. Yun, S. Dey, K.S. Nam, Zinc sulfide and terbium doped zinc sulfide films grown by traveling wave reactor atomic layer epitaxy // $\mathrm{J}$. Korean Phys. Soc. 33, p. 454-457 (1998). 